\title{
REVISÃO SOBRE O CONCEITO DE FORÇA: DA GRÉCIA ANTIGA AOS TEMPOS MODERNOS
}

\section{ARTIGO DE REVISÃO}

SOUSA, Jordana Yrla de Jesus ${ }^{1}$

MACÊDO, Haroldo Reis Alves de ${ }^{2}$

ALVES JÚNIOR, Pedro José Feitosa ${ }^{3}$

SOUSA, Jordana Yrla de Jesus. MACÊDO, Haroldo Reis Alves de. ALVES JÚNIOR, Pedro José Feitosa. Revisão sobre o conceito de força: Da Grécia Antiga aos tempos modernos. Revista Científica Multidisciplinar Núcleo do Conhecimento. Ano 05, Ed. 12, Vol. 10, pp. 135-156. Dezembro de 2020. ISSN: 2448-0959, Link de acesso: https://www.nucleodoconhecimento.com.br/fisica/tempos-modernos

\section{RESUMO}

O ensino de ciências nas escolas e em particular o de física, tem sido um dos grandes desafios para alunos e professores. O conceito de força é um exemplo de conteúdo que pode ser melhor explorado e para isso esse trabalho apresenta desde as primeiras visões filosóficas do conceito de força até chegar a construção científica desenvolvida por Newton, com o objetivo de oferecer ao professor uma forma de desenvolver a contextualização desse conceito tão importante e diminuir as barreiras de ensino e aprendizagem nos alunos do ensino médio. A metodologia utilizada foi um levantamento bibliográfico de diferentes autores que retrataram os principais eventos que levaram ao desenvolvimento do conceito de força, desde Aristóteles até as leis Newtonianas. Os principais resultados encontrados nessa revisão foi que o

\footnotetext{
${ }^{1}$ Graduanda do curso de Licenciatura em Física.

2 Orientador. Doutorado em Ciência e Engenharia de Materiais.

${ }^{3}$ Mestrado em Ensino de Física.
} 
conceito de força nasceu primeiramente através do pensamento filosófico e passou através da astronomia de forma não muito bem desenvolvida, mas necessária, e atingiu o seu ápice com Newton por meio do seu entendimento do movimento dos corpos celestes e a definição de força gravitacional.

Palavras-chaves: Força, Newton, Aprendizagem.

\section{INTRODUÇÃO}

Em 1986 Gabliardi já falava dos desafios que os alunos e professores tanto de escolas públicas quanto particulares tinham para se ensinar ciências, ele atesta essa realidade quando afirmou que várias experiências pedagógicas demonstraram que alunos não atingem um bom grau de aprendizagem em ciências e que essas dificuldades se devem a diferentes níveis escolares e sociais e que uma forma de superar esses desafios, é a utilização da história de ciências e epistemologia como um complemento das áreas mais desenvolvidas na pedagogia da ciência. A história das ciências e da Física, em especial, podem ser usadas no ensino de várias formas, para a: "determinação de obstáculos epistemológicos; para a definição de conteúdo do ensino; para introduzir na classe a discussão sobre a produção e controle de conhecimento a nível social e individual" (GABLIARDI, 1986, p. 254).

O objetivo deste trabalho foi reunir os principais pensamentos que levaram ao surgimento e evolução do conceito de força em Física, utilizando o conceito histórico, a fim de facilitar a abordagem desse tema na sala de aula, e dessa forma diminuir os déficits e resistências no ensino-aprendizagem de alunos.

\section{EVOLUÇÃO HISTÓRICA DO CONCEITO DE FORÇA}

O conceito de força, como todos os conceitos em ciência, é fruto de um longo desenvolvimento histórico, cujas origens não podem ser datadas com precisão. Para perceber a visão elaborada ao longo dos séculos sobre o conceito de força, dois aspectos básicos devem ser considerados como elementos de partida e suporte: a etimologia do termo e sua utilização extra cientifica (RADE, 2005). 
Segundo o site etimologia.com.br o termo força é originário do latim fortia que é associado ao adjetivo fortis interpretado como valentia que depois passou a ter conotação científica relacionando-se a capacidade de mover algo que tem peso ou que apresenta uma resistência (etimologia.com.br, 2020)

Apesar de existirem diferentes concepções para o conceito de força, quer pelo seu significado etimológico, quer pela sua conotação extra científica ou, até mesmo, pela enunciação de algumas das suas definições específicas, evidencia-se que o conceito de força acaba por ser indissociável do conceito de movimento. Essa percepção a priori permite perceber como se construiu o conceito de força até a contemporaneidade, tendo como ponto de partida os filósofos gregos, ou seja, a visão clássica ao conceito de força enunciado por Newton.

\subsection{VISÃO CLÁSSICA DO CONCEITO DE FORÇA}

A noção de força passou por um processo de análise filosófica profunda, concebendo a natureza como a substância primária como um ser vivente, provida de movimento próprio e dando origem (nascimento) às coisas individuais. $O$ essencial para os filósofos da época era apenas esse princípio único, o que os levava a uma questão de como os seres se diferenciavam a partir desta matéria primária.

Esses questionamentos, apesar de serem pensamentos filosóficos, criou uma discussão que deu lugar posteriormente à relação entre força e movimento. Segundo Polito e Filho (2013), essa corrente filosófica começou oficialmente em torno do final do século VII a.C com os filósofos Tales de Mileto (c. 624-546 a.C.), Anaximandro de Mileto (c. 610-545 a.C.) e Anaxímenes de Mileto (c. 585-526 a.C.).

De acordo com Cruz (1985), Tales acreditava que a água seria a matéria única, o princípio gerador de onde as demais se originavam, e que toda a constituição da natureza estava em constante transformação e em perpétuo movimento. Já para Anaximandro, o protoplasma seria a matéria prima, formado por uma substância útil que não era discernível. Ele ainda denominou outra matéria como aperion, esta, 
significa indeterminado ou ilimitado, porém, para Anaxímenes, segundo Cruz (1985), a matéria primária volta a ser uma substância natural como o ar ou vapor e que está diferenciada pela rarefação e condensação, onde os movimentos de convenção separavam as substâncias mais rarefeitas, que se deslocava para o universo, que formavam as estrelas e as mais condensadas, que formaram a terra. Desta forma 0 autor conclui que o movimento seria um tipo de propriedade inerente à matéria e um organismo vivo, pela qual a realidade física era agraciada de movimento, pois a natureza possuía uma alma imortal, e que sempre estava em movimento como os planetas, o sol e a lua.

Muitas ideias foram elaboradas nesse período, mas sem apresentarem grandes contribuições sobre o conceito de força, até o surgimento do que pode se chamar de "física aristotélica", baseada nos princípios da filosofia natural para explicar a força e o movimento dos corpos.

\subsubsection{ARISTÓTELES}

Aristóteles foi estudante de Platão, que viveu entre o período de 384 a 322 a.C. Ele tentou responder às diversas questões da natureza, procurou entender a conexão entre o movimento do sol, lua, e fenômeno das marés. Aristóteles foi um atento observador da natureza e tinha em mente que a terra representava um mundo em mudança constante com alterações climáticas, o nascimento e morte de seres vivos, representavam essas mudanças (CRUZ, 2009),

Para os aristotélicos, acrescenta Peduzzi (2011), a queda dos corpos, era um dos movimentos naturais que possuíam a finalidade manter a ordem na hierarquia de um do universo organizado, onde cada elemento ocupava o seu lugar natural.

De acordo com Peduzzi (2008), a certeza sobre sua lógica teórica, e a visualização sobre o que ocorria com a terra e o céu, fizeram com que Aristóteles criasse um modelo do universo. Essas interpretações, acrescenta Nascimento (2011), findou em uns lugares naturais, um conceito fundamental na visão da física aristotélica. Esse 
conceito, era um lugar natural do elemento terra, ou seja, sendo a Terra quase que totalmente constituída de terra, a própria devia estar centralizada no universo, teoria conhecida como geocêntrica.

Com o nascimento do geocentrismo, de acordo com Chalton e MacArdle (2017), Aristóteles estipulou que a Terra e os céus eram formados por cinco elementos (terra, água, fogo, ar e éter). Na Figura 1 tem-se uma representação imaginaria do modelo geocêntrico, onde os corpos celestes giravam em torno da terra. Nessa teoria cada corpo celeste era abrigado em um tipo de concha concêntrica e os elementos terrenos eram mortais, porém, os céus eram perfeitos e imutáveis.

Figura 1 - Sistema astronômico geocêntrico

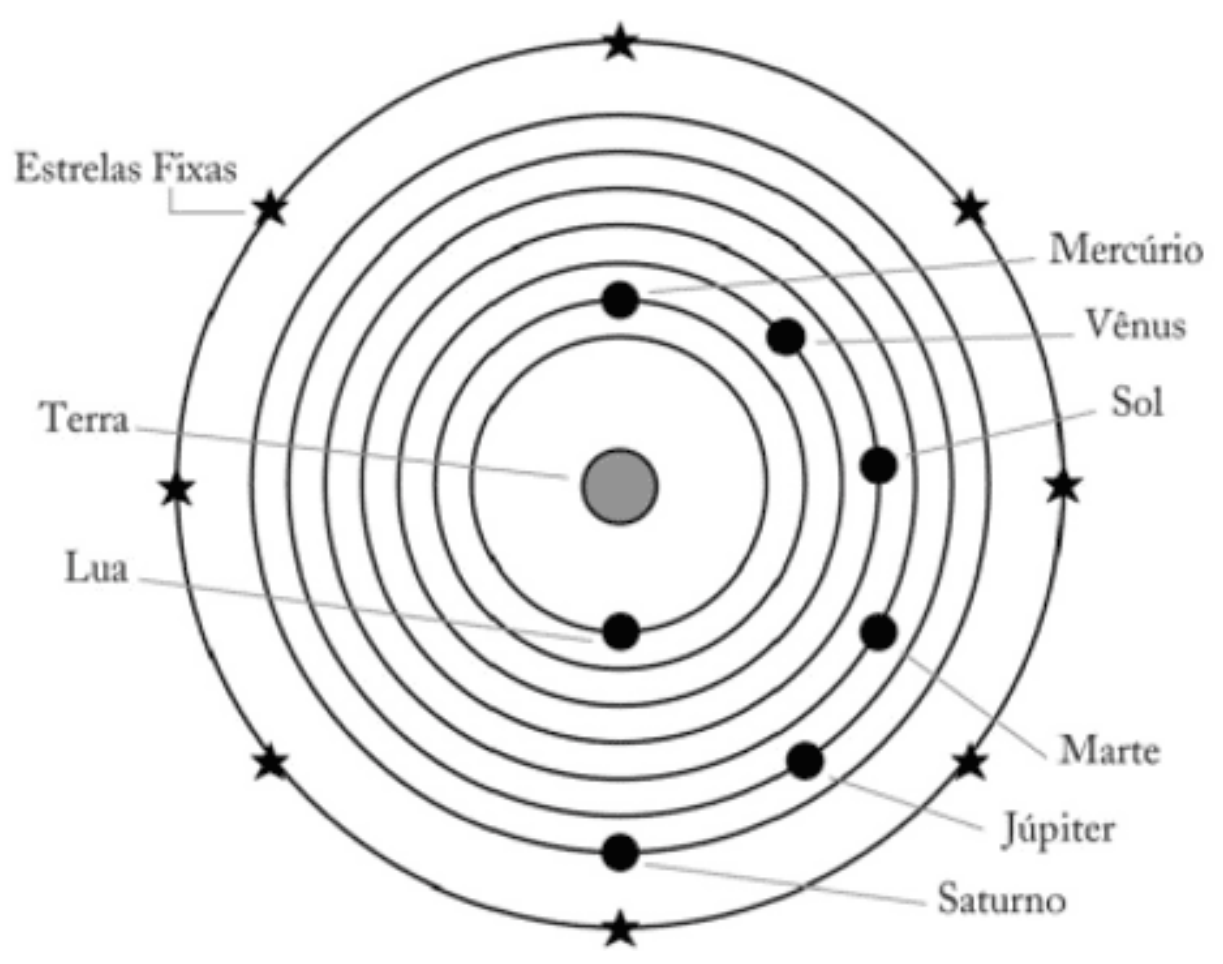

Fonte: CHALTON e MACARDLE (2017, p.13).

Segundo Cruz (1985), Aristóteles reconhece dois tipos de força: a força inerente à matéria (physis), que era responsável pelos movimentos naturais e a força como a liberação de um corpo (Força), em outras palavras, a força de empurrar ou puxar ocasionando em um movimento de impulsão sobre um segundo objeto foi nesse contexto, surgiu o conceito mais intuitivo e próximo do entendimento atual de força. 
Porém Aristóteles apresenta o seu conceito de força não mais como dissociada do elemento que a criou, e dessa forma, o que causa e o que move o movimento, devem estar em contato, pois para ele a ação a distância era intolerável.

Contudo, o questionamento central de Aristóteles não era entender por que um corpo se move, mas sim para que, e ele conclui que existe um lugar natural para todo corpo no universo. (ROCHA, 2002).

Outro conceito na visão aristotélica eram o de movimentos violentos. Como define Rocha (2002), esses movimentos são aqueles que se opõem aos naturais, e que sempre são provocados por fatores externos. Uma forma de se imaginar esses movimentos é o exemplo da Figura 2, onde ao se atirar uma pedra para cima, ela irá se distanciar do seu lugar natural, e assim que a ação acabar ela torna a cair buscando sua origem natural, pois na visão aristotélica o repouso no lugar natural é o estágio final que todos os corpos terrestres atingem, e que para deslocá-los é necessária uma ação violenta.

Figura 2 - O movimento violento e natural

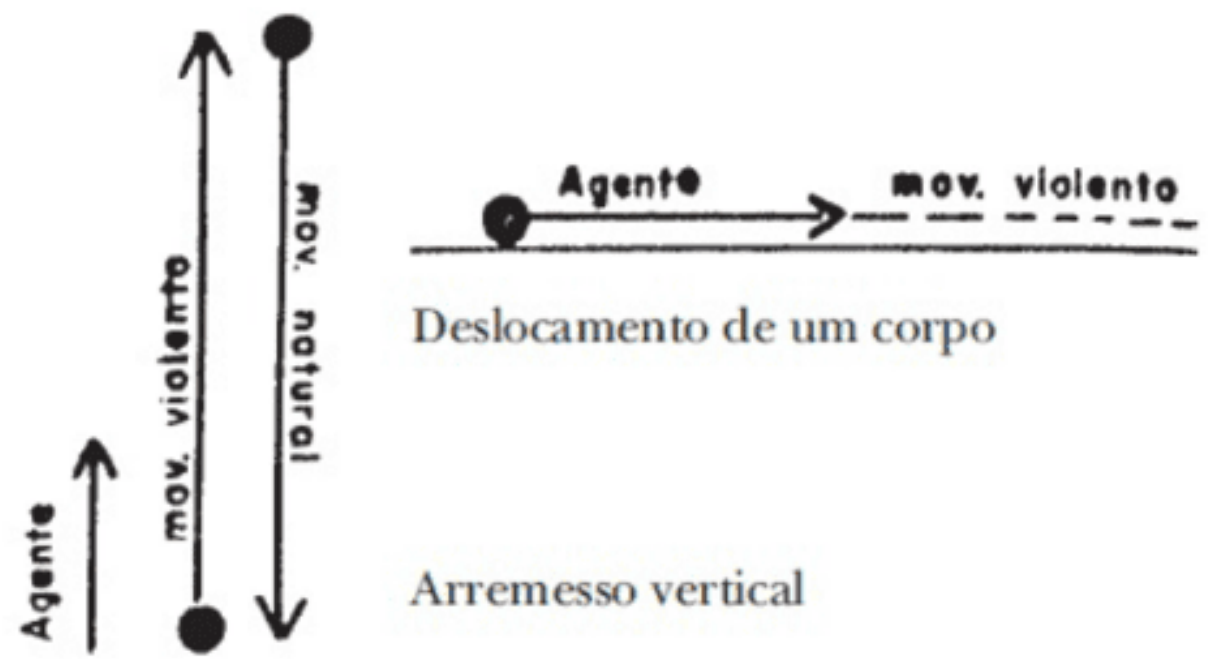

Fonte:

ROCHA (2002, p. 64)

Naquele período, Aristóteles não cogitava a possibilidade da existência de uma força gravitacional do universo que estaria na base do movimento da pedra que voltava a 
cair quando atirada para cima, justificando tudo pela ordem hierárquica natural dos corpos. Dito de outro modo, na mecânica aristotélica "todo corpo só pode ter um movimento de cada vez, de forma que um projétil que seja arremessado obliquamente terá uma trajetória retilínea ascendente até que a ação inicial se esgote e o corpo cairá verticalmente" (ROCHA, 2002, p.64).

No entanto, como explica Nascimento (2011), houve um grande debate acerca de corpos lançados, pois de alguma forma a permanência de movimento dos corpos depois do lançamento parecia ser uma evidência de que existia um movimento sem motivo aparente. Rocha (2002), afirma que: desejava-se saber qual era a força que causava o deslocamento do corpo depois de terminar o contato com o causador do movimento.

Assim, para explicar este problema, Nascimento (2011), destaca que Aristóteles recorreu àquilo que estava em contato com o projétil: o ar (meio). Para Aristóteles, um projétil em movimento ocupa o lugar que anteriormente estava preenchido pelo ar que existia em sua direção, esse ar fluía em torno do projétil para preencher o "vazio" que foi deixado por ele mesmo, isso exercia uma força que impulsionava o projétil. Esse processo em que o meio era o provisor de força motora, ficou conhecido como antiperístases.

Apesar da criação de novos argumentos havia dificuldades da física aristotélica para explicar as causas físicas do movimento não natural através do conceito das antiperístases (PEDUZZI, 2011), isso levou a Hiparco (190 a 120 a.C) a propor o conceito de força impressa, que era uma força interna armazenada no corpo e que seria responsável pelo movimento do projétil (NASCIMENTO, 2011).

A teoria mais bem elaborada sobre a força impressa, de acordo com Nascimento (2011), veio de Jean Buridan, professor da Universidade de Paris do século XVI. A teoria do Impetus conforme narra Nascimento (2011), seria uma força motriz incorpórea, inicialmente passada de um motor inicial para um corpo em 
movimentação, que se manteria no corpo, caso não sofresse alteração pela resistência do ar.

Apesar das contribuições da teoria do Impetus, Peduzzi (2011), afirma não existirem grandes diferenças em relação à física aristotélica e a força impressa do Impetus, uma vez que elas mantinham uma crença comum de que a permanência de um projétil em movimento só se tornava possível se nele agisse uma força/Impetus, ou seja, a velocidade de um objeto representava de forma equivocada, variações na intensidade da força/Impetus que o deslocava.

\subsubsection{PTOLOMEU}

Nascido no final do primeiro século da era cristã, Ptolomeu como narram Chalton e MacArdle (2017), adotou também a visão geocêntrica da Terra e foi o último dos grandes astrônomos da antiga Grécia tendo criado o primeiro modelo do universo, que explicou e e previu o movimento do Sol e dos planetas em linguagem matemática.

De acordo com Rocha (2002), na sua grande obra, o Almagest, Ptolomeu criou seu próprio modelo teórico planetário robusto, onde descreveu os movimentos complexos dos planetas, tendo como base a superposição de movimentos circulares com vários raios e centros. Neste modelo, Ptolomeu tentou responder às questões antigas, como do porquê um planeta girava em torno da Terra, ou do porquê um planeta parecia se mover em certas ocasiões para trás, em relação às posições fixas das estrelas.

$\mathrm{Na}$ Figura 3 apresenta-se o modelo Ptolomaico, onde é possível se observar o Deferente, o Epiciclo e o Equante. Nesse modelo as estrelas se encontravam distribuídas sobre uma superfície esférica concêntrica em relação à Terra (PEDUZZI, 2008).

Figura 3 - O deferente, o epiciclo e o artifício do Equante (Sistema de Ptolomeu). 


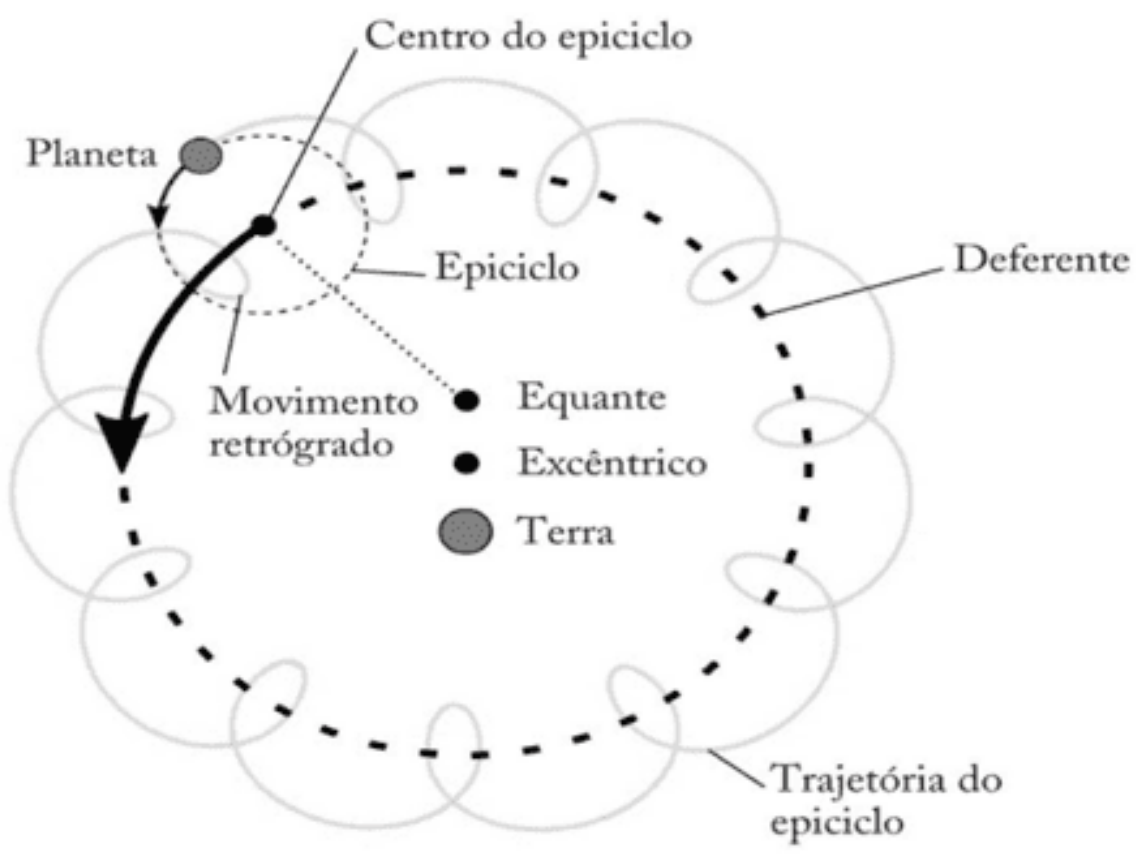

Fonte:

CHALTON e MACARDLE (2017, p.17).

Assim, com seu modelo geocêntrico, Ptolomeu situava a Terra não exatamente no centro das órbitas planetárias e apresentava uma descrição matemática detalhada dos movimentos do Sol e da Lua, capaz de prever, precisamente, as datas de futuros eclipses tanto solares quanto lunares, afirmam Chalton e MacArdle (2017).

\subsubsection{COPÉRNICO}

Em 1543 foi publicado o livro de Nicolau Copérnico (1473-1543) Sobre a Revolução das Órbitas Celestes (De Revolutionibus Orbium Caelestium), no qual Copérnico, apresenta um sistema astronômico matematicamente estruturado, capaz de rivalizar com o modelo geocêntrico altamente aceito na época (PEDUZZI, 2008).

Rocha (2002), afirma que inicialmente Copérnico imaginava que era possível a construção de um modelo de sistema onde o sol em repouso ocupa o centro, e os demais planetas, incluindo a Terra girariam em torno do sol em movimentos circulares, concêntricos e uniformes. Assim, segundo Cruz (2009), Copérnico estava convencido de que todos os planetas e inclusive a terra giravam em torno do sol, e dessa forma, Copérnico propôs um sistema heliocêntrico para o universo. 
Do ponto de vista físico, refere Nascimento (2011, p. 41), "o principal problema do modelo copernicano era explicar por que os corpos na superfície da Terra acompanhavam o seu movimento." Desta forma o modelo copernicana ainda necessitava responder por que os corpos continuavam a cair para o centro da Terra e não para o sol, já que este era supostamente o centro do universo, ou porque se estamos em rotação, não somos atirados para fora da Terra, e ainda porque uma pedra retorna para nossas mãos quando atirada para cima (ROCHA, 2002).

\subsubsection{KEPLER}

Depois de Copérnico, Johannes Kepler, matemático e astrônomo (1571-1630), foi o primeiro a defender de forma aberta uma teoria heliocêntrica do universo (CHALTON E MACARDLE, 2017)

Em 1600, Kepler começou a trabalhar com Tycho Brahe e recebeu deste a missão de determinar a órbita do planeta Marte, que apresentava discrepâncias bastante pronunciadas entre o que previam estes modelos e a trajetória do planeta no céu (PEDUZZI, 2008). Kepler, destaca Rocha (2002, p.80), "trabalhou durante longos oito anos contra a complexa trajetória de marte, até que, num lampejo de gênio, percebeu que todo o mistério poderia ser desvendado se considerasse a órbita de Marte como sendo uma elipse e não um círculo." Nascia assim a $1^{\text {a }}$ lei de Kepler que diz que "todos os planetas do sistema solar executam trajetórias elípticas tendo o Sol em um dos focos" (ROCHA, 2002, p. 80).

O que Kepler descobriu não foi apenas a órbita de Marte é uma elipse, mas que, além disso, o sol estava em um dos focos. Ele generalizou esse fato, às demais planetas de forma que cada planeta do sistema solar tem por órbita uma elipse com o Sol em um dos focos (PEDUZZI, 2008).

Deste modo, sintetiza Rocha (2002, p. 80), "cairia um dos mais antigos paradigmas da ciência grega: o círculo como figura perfeita, e quase sagrada, da qual derivariam todos os movimentos conhecidos." Todavia, asseveram Chalton e MacArdle (2017, 
p.27), "Kepler verificou também que uma linha imaginária unindo o centro do Sol a um planeta em movimento determina áreas que, se iguais, corresponderiam a tempos iguais de deslocamento do planeta." Assim tem-se a segunda lei de Kepler do movimento planetário ou lei das áreas que diz que a linha que liga o Sol aos planetas varre áreas iguais em tempos iguais (PEDUZZI, 2008) e (ROCHA, 2002).

O fato das velocidades orbitais dos planetas decrescerem com a distância ao Sol, com o consequente aumento dos correspondentes períodos de revolução, fez Kepler intuir que deveria haver uma relação de dependência entre esses dois parâmetros do movimento planetário, infere Peduzzi (2008). Dessa forma, acrescenta Rocha (2002, p. 81), "deveria haver uma relação íntima entre os períodos (tempo da órbita dos planetas) e as distâncias médias do planeta ao Sol." Esta relação é o que se conhece atualmente como a terceira lei de Kepler que diz que o quadrado dos períodos das órbitas dos planetas é proporcional ao cubo de suas distâncias médias ao Sol (ROCHA, 2002). Matematicamente, isso significa que quanto mais afastado do Sol, mais tempo o planeta leva para percorrer a sua órbita completa.

As leis do movimento planetário de Kepler, ressaltam Chalton e MacArdle (2007), foi de grande importância para destituir a ideia de planetas se movendo em órbitas perfeitamente circulares, crença que perdurou por mais de 2 mil anos. Os autores concluem que essas leis lançaram os alicerces para que Isaac Newton conseguisse estruturar a ciência moderna, tarefa que só foi cumprida oitenta anos depois. Porém, antes que Newton chegasse ao conceito de força, Galileu deu passos largos, uma base teórica mais palpável.

\subsubsection{GALILEU GALILEI}

O físico e matemático italiano, Galileu Galilei, nasceu em 15 de fevereiro de 1564 em Pisa Itália. Durante o intervalo de 1589 a 1609, quando atuou como professor nas universidade de Pisa e Pádua, desenvolveu o telescópio e os seus principais conceitos a respeito do movimento dos corpos (PEDUZZI, 2008). 
Em 1610, foi publicado "O Mensageiro das Estrelas", trabalho que causou muito incômodo na comunidade científica, e posteriormente foi motivo de perseguição a sua vida pessoal. "Porém, é em "Diálogo Sobre os Dois Principais Sistemas do Mundo" e em sua posição a favor de sistema de Copérnico, que Galileu, em 1632, foi acusado de Heresia pelo Santo Ofício e impedido de continuar os estudos sobre o sistema de Copérnico.

Em suas pesquisas e observações usando o telescópio, explica Peduzzi (2011, p. 94), "Galileu constatou que a sua superfície não era lisa, uniforme e perfeitamente esférica; mas áspera e desigual cheia de cavidades e saliências, à semelhança da Terra, com suas cadeias de montanhas e vales profundos." As experiências de Galileu foram fundamentais para o entendimento do movimento da Terra e desconstrução da visão aristotélica, como sustenta Rocha (2002), ter satélites não era um privilégio apenas da Terra e arrastá-los contrariava o argumento aristotélico de que, se a Terra se movesse, deixaria a Lua para trás. Deste modo, a Terra perdia o estatuto de ser 0 centro estático e privilegiado do universo.

Com base na sua metodologia, Galileu começa a analisar os movimentos investigando suas causas, como the haviam ensinado na universidade. Como relata Peduzzi (2008, p.121), "em De motu (Do movimento), trabalho que desenvolveu quando professor de matemática na Universidade de Pisa, Galileu também considera necessário associar uma força a um objeto em movimento para manter esse movimento".

Galileu entendia que quando um corpo, como uma pedra é lançada verticalmente para cima, é nela impressa uma força que possui certa virtude ou qualidade (força, Impetus), como consequência, o corpo ganha um tipo de leveza, e essa leveza é perdida na sua descida. (PEDUZZI, 2011),

Percebe-se que Galileu demonstrava-a ainda em certa medida, ser um defensor da força impressa e da teoria do Impetus formulada por Buridan. Pois acreditava que em um lançamento para cima, concentrava-se no corpo uma espécie de qualidade ou virtude (força), que diminuía na direção da subida e que essa força se equilibraria com 
seu peso e entraria em aceleração, essa por sua vez, seria o resultado da diferença do peso e a força impressa (NASCIMENTO, 2011)

Esses fatos, destaca Peduzzi (2008, p. 122), "sugerem um vínculo indispensável entre a aceleração de um corpo em queda e a força a ele impressa quando do seu lançamento para cima.".

O argumento aristotélico contra o movimento da terra era baseado em observações, como por exemplo, quando uma pedra é lançada, por exemplo, do alto de uma torre, ela cai na sua base e não ao oeste dela, como se pudesse supor que a terra girasse para o leste. Galileu rebate esse argumento afirmando que uma pedra abandonada do alto do mastro de um navio cairá sempre sobre o seu pé, o mesmo se daria quer o navio esteja em movimento uniforme ou parado, os peixes nadam no aquário, as moscas voam, a água goteja, atira-se um objeto, exatamente do mesmo modo (ROCHA, 2002).

Galileu explica, segundo Peduzzi (2008), que quando a pedra é solta, ela fica sujeita à ação simultânea de dois movimentos em horizontal, com velocidade constante, e outro vertical, com aceleração constante, isso significa que ao deixar a mão do lançador, a pedra conserva o seu movimento horizontal em relação à água, porque nessa direção não existe nada que a faça alterar o seu estado de movimento uniforme.

Apesar do seu esforço em entender a queda dos corpos, Galileu deixou muitos questionamentos em aberto, tais questões só começaram a ser melhor entendidas por meio de Descartes, que deu a Newton todo o embasamento e suporte necessário para a formulação três leis do movimento (ROCHA, 2002).

\subsection{VISÃO MODERNA DO CONCEITO DE FORÇA}

Pode se chamar o conceito moderno de força, àquele que nasceu com o pensamento de Descartes e se manteve até aos dias atuais com a visão elaborada por Newton. Nesse sentido, a ideia de um pensamento filosófico dá lugar a um modelo mais robusto e matemático, e foi Descartes quem deu esse ponta pé inicial. 


\subsubsection{RENÉ DESCARTES}

Nascido em Haye, França, René Descartes (1596-1650) fez grandes avanços na área da astronomia e mecânica, antecedidas pelas contribuições de Copérnico, Kepler e Galileu. Conforme conta Rocha (2002), era mais do que necessário fundar-se um novo sistema de pensamento, porém, a ideia da inércia é atribuída erroneamente a Galileu, pois foi Descartes quem expressou de forma clara a ideia de inércia.

Fundando uma nova forma de pensamento, as obras Discurso sobre o Método (1637) e Meditações Metafísicas (1641), Descartes estabeleceu sua estratégia filosófica de dúvida radical e sistemática, onde suspeitava da evidência dos sentidos e culminava nas ideias mais puras da razão, como as da matemática (POLITO, 2016). O que Descarte chama de mecanismo cartesiano, sintetiza Peduzzi (2011, p. 28), "é uma filosofia que postula que todos os fenômenos naturais devem ser explicados pelas leis da matéria em movimento", ou seja, sublinha Nascimento (2011, p. 46), para ele "o conhecimento se dava de forma dedutiva, a partir de ideias claras do intelecto humano e não por meio de observações de experiências."

De acordo com Peduzzi (2011), Descartes deduziu de forma incisiva que a quantidade de movimento do mundo é uma constante, pois Deus, segundo ele teria dotado a matéria de repouso, quanto de movimento indestrutível e eterno. Percebe-se que Descartes, interpreta corretamente o movimento e repouso de um corpo como estado da matéria. Na visão do mecanismo cartesiano e prevê ainda que o contato e o choque são as únicas possibilidades para dois corpos que estão interagindo, ou seja, Descarte percebe mudanças de quantidade de movimento, mas não a total do universo.

Dentre 37 páginas do seu livro original princípios da filosofia de 1644, Descartes tenta fundamentar sua dinâmica cartesiana, em três leis do movimento. Essas leis podem ser enunciadas segundo Medeiros (2017) como:

1) cada coisa permanecerá em seu estado se nada o mudar;

2) todo o corpo que se move tenderá a continuar o seu movimento em linha reta; 
3) se um corpo que se move encontrar outro corpo mais forte, seu movimento não diminui em nada;

A primeira lei, explica Rocha (2002, p. 70), "é uma espécie de princípio de inércia que Newton formularia com mais precisão nos Principia, enquanto que a segunda é uma lei geral dos choques." Ou seja, "é pelo contato direto dos corpos uns com os outros que se modificam estados de repouso e de movimento da matéria" (PEDUZZI, 2010, p. 33).

A terceira lei de Descartes acrescenta dois aspectos importantes, pois, segundo Polito (2016), revela uma interação entre uma noção de causa subjacente ou "força", e indica uma quantificação da forma devido ao movimento. Dessa maneira, entende-se que a terceira lei de Descartes se tratava da lei conservação de movimento.

Considerando a questão do porquê de os corpos arremessados continuarem a se mover após perderem o contato com o projetor do lançamento, levantados anteriormente por Aristóteles e Galileu, Peduzzi (2011) explica, que Descartes analisou que não havia motivos para tais corpos se moverem, pois só continuarão a se mover até o momento em que sofrem uma interferência de outros corpos.

Fica evidente pelas leis de Descartes, que foram elas em grande parte onde Newton se apoiou fortemente na criação da sua obra, dando finalmente a elaboração conceitual de força, da forma que é entendida e estudada nas escolas de ensino médio até os dias atuais.

\subsubsection{ISAAC NEWTON}

Isaac Newton nasceu em Woolsthorpe, uma cidade industrial inglesa, em Lincoln Shire, no dia de Natal, em 1642, conforme calendário Juliano adotado na Inglaterra na época. Newton, inspirou muitos trabalhos de arte e poesia, além de desenvolver o cálculo matemático, ele investigou a luz e através de experimentos e provou que a luz está relacionada com a cor (ROSINSKY, 2007), 
A partir das contribuições de Descartes, Kepler e Galileu, afirma Peduzzi (2010, p. 62), "a matematização de conceitos e leis físicas se torna uma exigência básica para a compreensão do mundo físico, contudo ainda inexiste uma definição quantitativa (em nível de consenso) para o conceito de força." Rocha (2002) diz que antes do advento do Principia de Newton (como ficou conhecido o livro Philosophiae Naturalis Principia Matemática), o conceito de força dos séculos XVI e XVII ainda estava impregnado de um aristotelismo do qual nem Descartes conseguiu se desvencilhar. Em 1687 ao publicar o Principia, Newton consolida a perspectiva inercial do movimento e da mecânica necessária para explicar os fenômenos terrestres e celestes (NASCIMENTO, 2011).

Enquanto a física cartesiana percebia força como uma ação de contato de um corpo sobre outro, o que implicava sua relação com a quantidade de movimento, a virada fundamental de Newton consistiu em mudar o foco do problema. Diferente de seus antecessores, Newton muda de ótica e começa a entender os processos dinâmicos como mudanças do estado do movimento de um único corpo, e não mais como troca de velocidades entre dois corpos, ou seja, durante esses processos, a ideia de força passou a estar vinculada com a medida de aceleração de um corpo (POLITO, 2016),

"É um mito a história de que uma maçã caiu na cabeça de Isaac Newton, mas é verdade que formulou sua teoria para explicar o fenômeno da queda dos corpos enquanto passeava pelo jardim, cogitando por que as maçãs caíam", esclarecem Chalton e MacArdle (2017, p.65). Newton por intuição associa a mesma força que faz uma maçã cair um pouco acima da superfície da terra, a força que faz a lua manterse acima da superfície da terra. É dessa forma que Newton desenvolve a gravitação.

Segundo Peduzzi (2010, p. 82) no Livro III dos Principia, "Newton investiga a lei da força centrípeta sobre um corpo cuja trajetória é uma elipse. Demonstra, então, que essa força varia com o inverso do quadrado da distância do corpo ao foco onde se acha o centro de força", Para Newton, afirma Rocha (2002, p.103), "a correlação da órbita lunar com a aceleração da maçã implicava numa lei do inverso do quadrado 
das distâncias que seria aplicável, não apenas a corpos situados próximos da superfície terrestre..." mas a também aos corpos celestes.

Newton imaginava que todas as partículas que formam a Terra se combinavam de forma a atrair tanto uma maçã, localizada a poucos palmos acima da superfície da Terra, como de centenas a milhares de quilômetros, como era o caso da lua, essa força tenderia a diminuir com o quadrado inverso das distâncias do centro da Terra (ROCHA, 2002)

Nota-se que o conceito de força para Newton estava atrelado ao seu intenso estudo da gravitação, tendo em vista que sua maior preocupação, na época, era descrever matematicamente os fenômenos planetários (NASCIMENTO, 2011). Segundo Polito (2016, p. 67), "ele conseguiu identificar o peso como uma força externa ao corpo, resultado da atração gravitacional universal." Essa descoberta marcou a história da física, pois fornecia uma explicação cosmológica para as órbitas planetárias e clarificava a queda dos corpos na superfície terrestre. Matematicamente a força gravitacional é descrita na equação 1.

$$
F=G \frac{M m}{d^{2}}
$$

\section{Equação (1)}

Onde F é a força gravitacional (força de atração) entre dois corpos pontuais com massas M e m separados a uma distância d e onde $G$ é uma constante de proporcionalidade, que possui o mesmo valor em todo o universo.

Newton ainda descreveu outro tipo de força, a qual Polito (2016) conta, que ele nomeia de força centrípeta, essa força tenderia de alguma maneira a ser mantida em torno de um ponto central, além disso, é através dessa força, que Newton insere a força que age a distância, nisso ele se refere à força de atração gravitacional, afirmando que todos os corpos no Universo, por terem massa, exercem forças de atração granítica uns sobre os outros (POLITO, 2016). 
Outro termo que Newton conseguiu encontrar um significado mais amplo foi o de força impressa, Polito (2016, p.68) explica que, ele "usou a expressão força impressa, definindo-a como sendo "uma ação exercida sobre um corpo, com o intuito de mudar seu estado, seja de repouso, seja de movimento retilíneo uniforme". Newton explicou como forças e massas agem umas sobre as outras para criar movimento e apresentou três leis para o movimento

Lei I: "Todo corpo continua em seu estado de repouso ou de movimento uniforme em uma linha reta, a menos que ele seja forçado a mudar aquele estado por forças imprimidas sobre ele" (NASCIMENTO, 2011, p. 50). Essa lei pode ser também chamada lei da inércia e confirmou as ideias do cientista italiano Galileu Galilei, que estudou o movimento dos pêndulos e a queda dos corpos. Essa lei revolucionava o pensamento clássico sobre o movimento dos corpos.

Halliday e Resnick (1983) ainda deduzem que na primeira lei não existem diferenças entre a ausência de quaisquer forças e a presença de forças cuja resultante seja nula. Os autores afirmam ainda que, a primeira lei de Newton é uma afirmação sobre referenciais, pois, de um modo geral a aceleração de um corpo dependerá do sistema de referência em relação ao qual se está sendo medida.

Lei II: "A mudança de movimento é proporcional à força motora imprimida, e é produzida na direção da linha reta na qual aquela força é imprimida" (NASCIMENTO, 2011 , p. 50). Nessa lei, que é descrita na forma da equação 2, Newton apresenta a relação entre a massa de um corpo $(m)$, sua aceleração (a) e a força nele aplicada $(\mathrm{F})$.

$$
\vec{F}_{R}=m \vec{a}
$$

Onde é a força resultante (em N) que atuam no corpo, é a massa inercial dada em $\mathrm{kg}$ e é a aceleração adquirida pelo corpo em $\mathrm{m} / \mathrm{s}^{2}$. 
Lei III: "A toda ação corresponde uma reação com a mesma intensidade, mesma direção e sentidos contrários" (CHALTON e MACARDLE, 2017, p. 66). Com essa lei, Newton apresenta uma importante característica do conceito de força, seu aspecto dual, chamado hoje de princípio da ação e reação. Essa terceira lei de Newton permitiu que se explicasse muitos movimentos, desde o da natação (quando a pessoa nada empurra a água para trás e a água reage, impulsionando a pessoa para frente) ao de carros derrapando sobre superfícies cobertas com uma camada de gelo (CHALTON E MACARDLE, 2017).

De um modo geral, Newton, em no Principia, seja pela lei da gravidade e sobretudo pelas três leis do movimento, apresenta os fundamentos que passaram a reger a dinâmica (parte da Física que busca conhecer as causas dos movimentos), originando daí o conceito de duas grandezas (massa e a força) e, consequentemente, o conceito de algumas forças notáveis da natureza.

Rocha (2002) conclui que Os Principia de Newton concentra de forma tão perfeita toda a ciência feita até então, que posteriormente o pensamento científico foi em grande parte a consolidação e o aprimoramento da mecânica newtoniana.

\subsection{FORÇAS FUNDAMENTAIS DA NATUREZA}

A evolução do conceito de força se viu consolidada com as três leis de Newton, que passaram a explicar a maior parte dos fenômenos e interações que ocorrem na natureza através da força, sublinhando-a como a causa dos movimentos dos corpos. Porém, as leis de Newton chegaram a um limite, pois conseguem apenas circundar um conjunto de forças, sobre as quais os corpos são de grande tamanho, elas também não conseguem descrever as chamadas forças fundamentais ou interações, que acontecem em todas as escalas de nível macroscópico a microscópico (LALIC, 2007).

Nas várias partes do Universo encontram-se numa interação natural, permanente e constante, independentemente do tamanho. Segundo Menezes (2005) as quatro 
diferentes forças encontradas hoje na natureza são a gravitação, o Eletromagnetismo, a Interação forte e a Interação fraca, e atuam por princípios diferentes".

\subsubsection{FORÇA GRAVITACIONAL}

Tanto o movimento de translação da Terra como a queda dos objetos em direção à superfície terrestre ocorrem devido à força gravitacional que é uma força atrativa e de ação a distância entre dois objetos quaisquer (KNIGHT, 2009).

Nas palavras de Lalic (2007, p. 366), "é a ação da força gravitacional que determina as órbitas dos planetas, estrelas e galáxias, assim como os ciclos de vida das estrelas e a evolução do próprio Universo." Se comparada as demais interações fundamentais a gravidade é a mais fraca, no entanto, ela é uma força que age a longo alcance, isso significa que não existem limites de distância para os corpos interagirem.

\subsubsection{FORÇA ELETROMAGNÉTICA}

De acordo com Frenkel (1996, p. 17), "esta força de interação depende de uma característica fundamental das partículas, denominada carga elétrica." A interação entre partículas de espécies distintas tem uma natureza tanto repulsiva, quanto atrativa. Para tal, são adotadas convenções: o elétron passa a ser caracterizado com carga negativa e os prótons são carregados positivamente. De forma que cargas de mesmo sinal sofrem repulsão, e cargas de sinais opostos são atraídas entre si.

Peruzzo (2012) ressalta que essencialmente, as forças do macroscópico, exceto a força gravitacional, são manifestações das forças eletromagnéticas, quando avaliadas mais profundamente. Isso significa que todas as forças de atrito e tensão, são no fundo um resultado de forças eletromagnéticas entre partículas vizinhas carregadas

\subsubsection{FORÇA NUCLEAR FORTE}

Admas (2001) explica que os núcleos atômicos funcionam como estruturas bem sincronizadas, porque a interação forte possui o poder para manter os prótons unidos, 
lutando contra a repulsão elétrica dos prótons, que age no sentido de desintegrar o núcleo. Já de acordo com Carvalho (2020) os dois níveis de interação da força forte ocorrem em um primeiro nível entre núcleos, por meio da troca de mésons, partículas compostas por um quark e sua antagonista antiquark de cores opostas, essas partículas são isoladas dando origem a prótons e nêutrons.

A outra interação forte, completa Carvalho (2020) ocorre entre quarks e glúons, partículas sem massa, que funcionam como uma espécie de "cola", carregando a chamada carga de cor, porém, sem carga elétrica. Uma maneira de se entender a interação dessas partículas é por meio da representação artística da figura 4, o próton em formação nesse exemplo é formado por dois quarks up (cima) e um quark down (baixo), e o glúon é a partícula que segura essa interação, lembrando que as cargas de cores dos quarks são necessárias e distintas.

Figura 4 - Representação visual de dois quarks up (u) e um quark down (d) do próton.

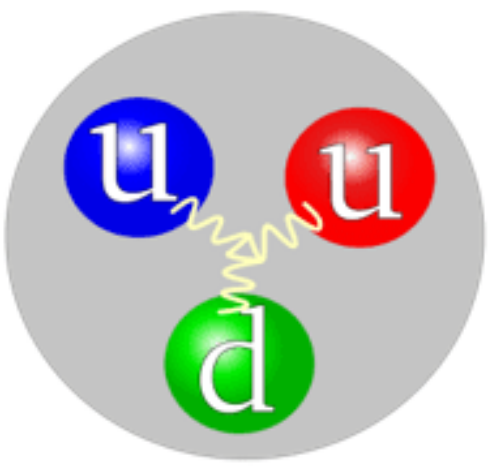

Fonte: Wikipédia (2020)

$\mathrm{Na}$ verdade, os físicos haviam notado que apesar de existir grande repulsão eletromagnética entre os prótons, o núcleo atômico permanecia estável. Essa estabilidade nuclear é criada pela presença de um novo tipo de interação entre partículas, a força nuclear forte, que mantém o núcleo atômico unido, explica Lalic (2007). Assim sendo, "se os núcleos atômicos não existissem, os átomos não existiriam, nem as moléculas. Deste modo, os seres humanos, que são formados por moléculas, também não existiriam" (LALIC, 2007, p. 369).

\subsubsection{FORÇA NUCLEAR FRACA}


Além dos fenômenos explicados pela força nuclear forte, no núcleo atômico acontece outros que, apesar de estarem relacionados com a estabilidade nuclear, são explicados pela força nuclear fraca. Ela, de acordo com Carvalho (2020), é a força que provoca o decaimento radioativo dos núcleos atômicos. De forma que ela rege todo o processo de emissão beta no qual um nêutron divide-se em um próton, um elétron e um anti-neutrino.

Do mesmo modo que a força nuclear forte, a força fraca também é uma força de curto alcance, pois atua somente em uma vizinhança de cerca de $10^{-16}$ centímetros (LALIC, 2007). A tabela 1 sintetiza o alcance e a intensidade relativa de cada uma das forças fundamentais da natureza.

Tabela 1 - Magnitude e Alcance das Forças Fundamentais

\begin{tabular}{|l|l|l|l|}
\hline Força (ou interação) fundamental & Mediador & Magnitude relativa & Alcance \\
\hline Forte & Glúon & $10^{38}$ & $\sim 10^{-15}$ \\
\hline Eletromagnética & Fóton & $10^{36}$ & $\infty$ \\
\hline Fraca & Bósons W e Z & $10^{25}$ & $\sim 10^{-18}$ \\
\hline Gravitacional & Gráviton & $10^{1}$ & $\infty$ \\
\hline
\end{tabular}

Fonte: adaptado de (LALIC, 2007)

Tanto a força nuclear forte como a força nuclear fraca estão presentes no núcleo atômico e não são observadas no cotidiano. Na verdade, explica Netto e Telles (2018), as forças forte e fraca só se tornaram conhecidas após a descoberta do nêutron, como resultado da busca para entender como o nêutron pode ficar no interior do núcleo, já que não tem carga elétrica, para ligá-lo ao próton. Elas, acrescenta o autor, só são importantes em escalas de distâncias muito pequenas, da ordem do tamanho do núcleo atômico, por isso não são observadas diretamente no nosso dia a dia. 


\subsubsection{FORÇA DE CAMPO E FORÇA DE CONTATO}

As forças podem ainda ser divididas em duas categorias: forças de campo e forças de contato. Para que haja interação entre os objetos, não há necessidade de que eles estejam próximos, fazendo como que nas forças de campo surjam interações entre objetos mesmo que eles estejam muito longe uns dos outros, através de algo que faz ligação entre os objetos: um campo de forças (MARQUES, 2014).

Nessa categoria, exemplifica Lalic (2007), fazem parte tanto à força gravitacional, que acontece, por exemplo, quando uma pedra é atirada para o alto e ela é atraída para o solo; como a força eletromagnética, observada quando um imã é aproximado da geladeira.

Por outro lado, refere Marques (2014, p. 116), "as forças de contato são aquelas que resultam do contato físico entre duas superfícies ou o contato de um objeto com um fluido." É o caso da força normal e das forças de atrito.

\subsubsection{FORÇA NORMAL}

De acordo com a figura 5, o fato de um livro repousar sobre uma mesa, ocorre porque a mesa exerce uma força sobre o livro perpendicular à superfície horizontal da mesa, ela por sua vez equilibra a força da gravidade impedindo que o livro caia no chão, sendo essa força chamada de força normal - N, que é sempre perpendicular à superfície (MARQUES, 2014).

Figura 5 - Representação da força normal. 


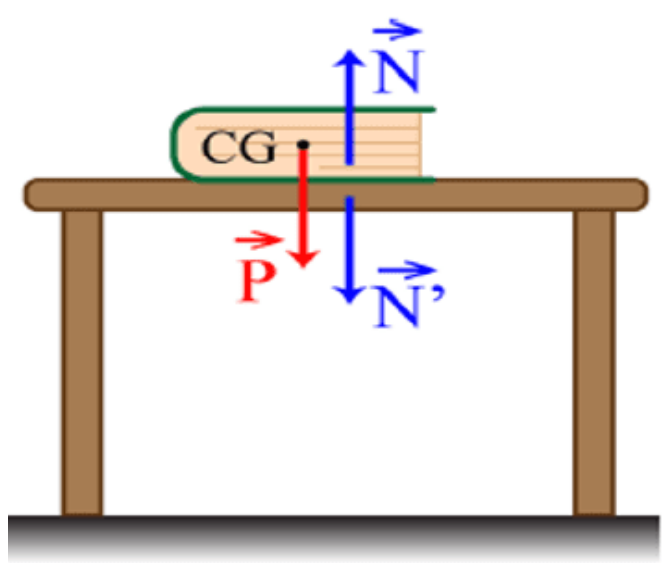

$\vec{P}=$ força peso (interação gravitacional)

$\vec{N}^{\prime}$ = força normal (força de contato que a mesa exerce no livro).

$\vec{N}=$ força normal (força de contato que o livro exerce na mesa)

Fonte: MARQUES (2014, p. 125)

\subsubsection{FORÇAS DE ATRITO}

A força de atrito designa um tipo de força cuja ação é resistir aos movimentos relativos que envolvem superfícies sólidas, camadas de um fluído ou corpos materiais em contato. Está pode subdividir-se em dois tipos: as forças de atrito estático, que atuam entre superfícies em repouso relativo; e as forças de atrito cinético, que acontece entre superfícies que têm movimento relativo (MARQUES, 2014) e (SILVA, 2002).

Por fim, em resumo essas são as principais forças que atuam e estruturam todo o universo, forças estas que só foram entendidas partir de um longo esforço coletivo entre o pensamento filosófico, até chegar à física newtoniana.

Conforme explica Gabliardi (1983), fica a cargo dos professores utilizarem a parte histórica das ciências, nesse caso à física, para suplementar o seu conceito matemático, usando de bom senso quando e de que forma trabalhar o conteúdo em sala de aula.

\section{CONSIDERAÇÕES FINAIS}

O presente trabalho procurou descrever o conceito de força, através da sua evolução histórica. Com base na revisão bibliográfica desse estudo, ficou esclarecido, que a noção de força, nos primórdios da sua construção conceitual, esteve relacionada com 
o movimento dos corpos celestes, porém, o movimento nem sempre foram explicados devido a presença de força.

De Aristóteles a Ptolomeu, defendeu-se uma doutrina geocêntrica, considerando a Terra como o centro do universo e explicando, paralelamente, o movimento dos corpos segundo uma hierarquia natural dos corpos, sem existir quaisquer preocupações com a possibilidade de existir uma força de campo que pudesse atrair os corpos para o centro da terra. A partir de Copérnico, surgiu a visão heliocêntrica, colocando o sol no centro do universo. Esta visão foi consolidada por Kepler e Galileu.

As leis estabelecidas por Newton: lei da gravidade e as 3 leis do movimento dos corpos permitiram sustentar a ideia que uma força imprimida consiste somente na ação e não mais permanece no corpo, trazendo assim uma visão científica de força e seus conceitos são estudados até hoje e tem aplicação no cotidiano.

Por fim, essa revisão histórica propiciou uma visualização de como a física pode ser contextualizada, a fim de se trabalhar o conceito de força na sala de aula, cabendo ao professor adaptar a historicidade das ciências, podendo ser usada para se alcançar um melhor entendimento e consequentemente um melhor rendimento do ensinoaprendizagem dos alunos no ensino médio.

\section{REFERÊNCIAS}

ADMAS, Fred. Uma Biografia do Universo: do big bang à desintegração Final, 1 ed. Rio de Janeiro: Jorge Zahar Ed., 2001.

ARAÚJO, Mariana de. Lei da gravitação universal. Rev. Ciência Elem., V1(1):013, p. 2, 2013.

CARVALHO, Alexandre. Mecânica Quântica, 1 ed. São Paulo: clube dos autores, 2020. 
CHALTON, Nicola; MACARDLE, Meredith. A história da ciência para quem tem pressa, 1 ed. Rio de Janeiro: Valentina, 2017.

CRUZ, F. F. de Souza. O conceito de força no pensamento grego. Cad. Cat. Ens. Fis., Florianópolis, 2(1), p. 16-24, 1985.

FORÇA. In: https://etimologia.com.br/forca/. Acesso em: 10/12/2020.

FORÇA. In: etimologia.com.br DICIO, Dicionário da Língua Portuguesa. Porto: 7Graus, 2020. Disponível em: < https://www.dicio.com.br/forca-3/>. Acesso em: 25/04/2020.

FRENKEL, Josif. Princípios de Eletrodinâmica Clássica, 2 ed. São Paulo: EDUSP, 2017, vol.1.

GAGLIARDI, R. La Historia de las Ciencias: Una Herramienta para la Enseñanza. Enseñanza de las Ciencias, 4 (3), p. 253-258, 1986.

HALLIDAY, D.; RESNICK, R. Física 1, 4 ed. Rio de Janeiro: LTC - Livros Técnicos e Científicos Editora S.A., 1983, vol. 1.

KNIGHT, Randall D.. Uma Abordagem Estratégica - Mecânica Newtoniana, Gravitação, Oscilações e Ondas, 2 ed. São Paulo: Bookman, 2009, vol. 2.

LALIC, Suzana de Sousa. Introdução à Física, 1 ed. São Cristóvão: Universidade Federal de Sergipe, CESAD, 2007.

MARQUES, Gil da Costa. Dinâmica do Movimento dos Corpos. Material do Curso de Licenciatura em Ciências. São Paulo. 2014. Centro de Ensino e Pesquisa (CEPA) do Instituto de Física da Universidade de São Paulo.

MCLEISH, Kenneth. Aristóteles: a poética de Aristóteles, 1 ed. São Paulo: Unesp, 2005. 
MEDEIROS, Djalma. Descartes e o fundamento metafísico da inércia natural dos corpos na correspondência com Mersenne. Revista de Filosofia do IFCH da Universidade Estadual de Campinas, 2017, v. 1, n. 2, jul./dez. Disponível em: < https://www.ifch.unicamp.br/ojs/index.php/modernoscontemporaneos/article/view/325 9/2497>. Acesso em: 16/05/2020.

MENEZES, Luís Carlos de. A matéria, 1 ed. São Paulo: Livraria da Física, 2005.

NASCIMENTO, Wilson Elmer. História do desenvolvimento do conceito de força: um estudo visando contribuições para o ensino de física no nível médio. 2011. Trabalho de conclusão de curso (Licenciatura em Física) - Universidade Estadual Paulista, Faculdade de Engenharia de Guaratinguetá, São Paulo, 2011. Disponível em: <http://hdl.handle.net/11449/120162>. Acesso em: 19/04/2020.

NETTO, Dirceu D’Alkmin; TELLES, João Mongelli. Física com aplicação tecnológica: Eletrostática, eletricidade, eletromagnetismo e fenômenos de superfície, 1 ed. São Paulo: Blucher, 2016, vol.1.

PEDUZZI, Luiz O. Q. Da física e da cosmologia de Descartes à gravitação newtoniana. Apostila do Departamento de Física. Florianópolis. 2010. Universidade Federal de Santa Catarina (UFSC).

PEDUZZI, Luiz O. Q. Evolução dos Conceitos da Física. Apostila do Departamento de Física. Florianópolis. 2010. Universidade Federal de Santa Catarina (UFSC).

PEDUZZI, Luiz O. Q. Força e Movimento: de Thales a Galileu. Apostila do Departamento de Física. Florianópolis. 2010. Universidade Federal de Santa Catarina (UFSC).

PERUZZO, Jucimar. Fronteiras da Física: Tópicos de Física Moderna e Contemporânea, 1 ed. Irani: Clube dos Autores, 2012, Vol. 3. 
POLITO, Antony M. M.. A construção da estrutura conceitual da física clássica 1 ed. São Paulo: Livraria da Física, 2016.

POLITO, Antony Marco Mota; SILVA FILHO, Olavo Leopoldino da. A filosofia da natureza dos pré-socráticos. Caderno Brasileiro de Ensino de Física, v. 30, n. 2, p. 323-361, ago. 2013.

QUARK. Wikipédia, 2020. Disponível em: <https://pt.wikipedia.org/wiki/Quark>. Acesso em: 01/07/2020.

ROCHA, Jose Fernando M.. Origens e Evolução das Ideias da Física, 1 ed. Salvador: EDUFBA, 2002.

ROSINSKY, Natalie M.. Isaac Newton: Brilliant Mathematician and Scientist, 1 ed. Canberra: Capstone, 2007. 